\title{
Forest inventory and monitoring information to support diverse management needs in the Lake Simcoe watershed
}

\author{
by Aaron N. Day ${ }^{1}$ and Danijela Puric-Mladenovic ${ }^{2}$
}

\begin{abstract}
Analysis using the Vegetation Sampling Protocol (VSP) pilot data collected in the Lake Simcoe watershed (2011) was done to assess the protocol's effectiveness in supporting natural heritage monitoring for the Lake Simcoe Protection Plan (LSPP). The VSP data was analyzed and assessed in the context of information needs for forest management and conservation. Specific information needs to support forest management are used as a criterion for stand analysis. While a variety of inventory approaches and methods are used in the Lake Simcoe watershed, most are done for specific purposes or lack necessary stand-level, compositional and structural information to inform biodiversity reporting, monitoring, and other management objectives of the LSPP. The study has shown that VSP plot data can be used to meet the requirements of the LSPP and further support the requisite information for active forest management. Stand analyses provide insight into the varying conditions of the Lake Simcoe watershed forests and can steer future analysis and comparisons.
\end{abstract}

Key words: Lake Simcoe, forest inventory, ecological monitoring, forest management, conservation planning, southern Ontario

\section{RÉSUMÉ}

Une analyse des données préliminaires du protocole déchantillonnage de la végétation (PEV) recueillies dans le bassin hydrographique du lac Simcoe (2011) a été effectuée afin dévaluer l'efficacité du protocole à permettre le suivi de la biodiversité tel qu'inclus dans le plan de protection du lac Simcoe (PPLS). Les données du PEV ont été analysées et évaluées dans un contexte de recherche d'informations destinées à l'aménagement et à la protection des forêts. Les informations spécifiques requises pour appuyer l'aménagement forestier sont utilisées en tant que critères d’analyse des peuplements. Même si plusieurs approches et méthodes d'inventaire sont utilisées dans le bassin hydrographique du lac Simcoe, la plupart répondent à des objectifs spécifiques ou ne contiennent pas les informations requises au niveau des peuplements, de leur composition et de leur structure permettant de faire état de la biodiversité, du suivi et des autres objectifs de gestion du PPLS. Létude a démontré que les données des parcelles du PEV peuvent être utilisées pour répondre aux exigences du PPLS et pour en plus apporter des informations nécessaires dans le cas d'un aménagement forestier en voie de réalisation. Les analyses des peuplements permettent détablir une vision interne des différentes conditions retrouvées dans les forêts du bassin hydrographique du lac Simcoe et font en sorte de générer des analyses et des comparaisons plus poussées.

Mots clés : lac Simcoe, inventaire forestier, suivi environnemental, aménagement forestier, planification de la conservation, sud de l'Ontario

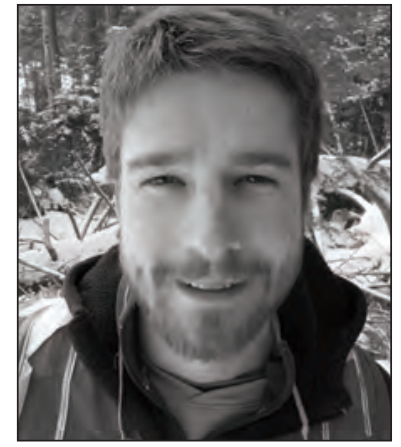

Aaron N. Day

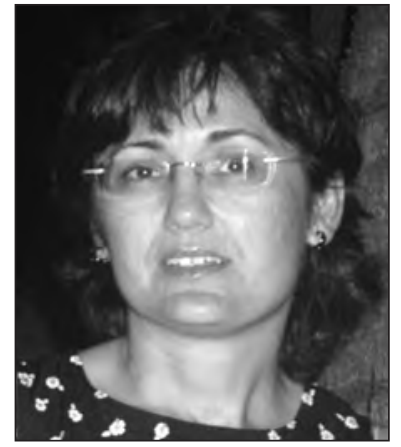

Danijela Puric-Mladenovic

\section{Introduction}

Forest structure, composition, health and the amount of forest cover define and influence ecological functions and services forests provide in the Lake Simcoe (LS) watershed. The Lake Simcoe Protection Plan (OME 2009) outlines that the health of the entire watershed must be addressed and that both aquatic and terrestrial systems must be monitored, conserved and remediated. As a result, a terrestrial natural heritage monitoring program was mandated to enable reporting on the biodiversity, ecological health, and habitat quality of the natural heritage of the LS watershed (OME 2009, Chapter 6).

The already-fragmented remnant forest cover in the watershed is threatened by land conversion, development and

\footnotetext{
${ }^{1}$ Faculty of Forestry, Earth Sciences Centre, 33 Willcocks St., Toronto, Ontario M5S 3B3. E-mail: aaron.day@utoronto.ca

2 Information Management and Spatial Analysis, Southern Science and Information Section, Ministry of Natural Resources, 300 Water St., $4^{\text {th }}$ Floor South Tower, Peterborough, Ontario K9J 8M5. E-mail: danijela.puricmladenovic@ontario.ca

Faculty of Forestry, University of Toronto, 33 Willcocks St., Toronto, Ontario M5S 3B3.
} 
growth of urban areas (LSSAC 2008). Moreover, climate change and its concomitant effects on forest biodiversity and functions will magnify the existing anthropogenic impacts and disturbances, and increase pressure on forest ecosystems (Brinker and Jones 2010). These combined influences require adaptive and timely management decisions and actions that aim to sustain not only the health and biodiversity of the forests, but also the ecological goods and services that people inhabiting the area receive from forests. However, adaptive and timely management actions are triggered, informed and highly dependent on the quality and quantity of information that can be derived from forest inventory and monitoring programs.

In the LS watershed there is a lack of consistent and standardized forest inventory information that is updated on a regular basis and that enables the measurement and evaluation of forests over time. Strategic and comprehensive inventory is required to support forest management and conservation needs that range from timber harvesting, and regeneration and seed source management, to wildlife and species at risk habitat conservation and management, biodiversity protection and enhancement, biomass and ecosystem services estimations, climate change monitoring, and invasive species management (Noss 2004, Puric-Mladenovic et al. 2010).

A number of forest information and inventory strategies have been used in the LS watershed. Land use mapping such as the Southern Ontario Land Resource Information System (SOLRIS) captures fine spatial details of forest extent, but only generalizes forest classes (e.g., coniferous, deciduous, and mixed). Forest Resource Inventory (FRI) has not been conducted since 1978 in the watershed, nor has this original information been converted to GIS format. Since the midnineties, Ecological Land Classification (ELC) has been widely used in Southern Ontario (Lee et al. 1998, OMNR 2010) to map and classify forest vegetation. The three approaches are deficient at estimating changes and supporting monitoring needs (Gillis 1988) due to the nature of their sampling, inability to replicate samples, variable size of sampling unit (stand/polygons are of different size), sensitivity of vegetation classes to changes and interpretation, and shifts in vegetation boundaries.

The Canadian National Forest Inventory (NFI) has only one plot (OMNR 2010) in the LS watershed, and the Ontario Ministry of Natural Resources program, Growth and Yield (G\&Y), has 41 plots in the watershed. NFI and G\&Y plots are inadequate to support stand level applications and regional management and modeling (Gillis 2001; Gillis et al. 2005, 2010; Yemshanov et al. 2011) due to their limited distribution. While both of these can be used to describe tree composition and structure (i.e., density, basal area) as well as provide information on seed source, biomass estimates, and habitat, their time-intensive and time-consuming process of sampling limits their wider and more intensive application.

The Vegetation Sampling Protocol (VSP) (Puric-Mladenovic et al. 2009) has been used in Southern Ontario more intensively since 2005 resulting in over 6,000 vegetation plots. The VSP is also similar to the monitoring plots of NFI and G\&Y (Roberts-Pichette and Gillespie 1999, Drysdale et al. 2007, Puric-Mladenovic et al. 2009, Gillis et al. 2010), but has an emphasis on a diversity of practical applications, easy implementation and usability by different user groups. VSP, while based on rigorous sampling standards, has a modular approach that allows flexibility in terms of sampling intensity at the location. For example, VSP allows sampling minimal information per plot as well as in-depth sampling, depending on the available resources, inventory application and information needs. VSP has been piloted in the LS watershed (2011) to gather baseline data and assess its applicability to support monitoring and management. The plots were also put in place to start a long-term monitoring network, provide data to assess current state and composition of forests, and to establish a baseline dataset (OMNR 2010).

The objective of this study was to determine and demonstrate how the selected VSP approach and its collected baseline data can be used to support the diverse information needs for forest management and provide a framework for forest inventory, reporting, and monitoring in order to meet the requirements of the LSPP. Further, the study demonstrates how the plot-based information may be used to not only answer questions regarding the current state of forests in the watershed and LSPP monitoring, but to also provide the necessary information for forest management decision-making.

\section{Methods \\ Study site}

The LS watershed lies within the southern area of the Great Lakes - St. Lawrence Forest Region (Rowe 1972) of Ontario. It is within Ecoregion 6E (OMNR 2006), and is almost entirely overlapping with Eco-district 6E6. About $34 \%$ of the Lake Simcoe watershed is in some form of forest cover. The amount of forest cover varies by quaternary watershed and it ranges from $14 \%$, in areas of more productive agricultural soils, to $79 \%$ where soils are less suitable for agriculture and land development (e.g., over 40\% forest cover) (Puric-Mladenovic et al. 2010).

The natural forests in the watershed are dominated by deciduous tree species such as sugar maple (Acer saccharum Marsh.), red maple (Acer rubrum L.), yellow birch (Betula alleghaniensis Britt.), red oak (Quercus rubra L.), basswood (Tilia Americana L.) and white elm (Ulmus americana L.) with some coniferous cover of white pine (Pinus strobus L.), red pine (Pinus resinosa Ait.), and eastern hemlock (Tsuga canadensis [L.] Carrière). Other wide-ranging species in the area include eastern white cedar (Thuja occidentalis L.), American beech (Fagus grandifolia Ehrh.), white oak (Quercus alba L.) and white ash (Fraxinus Americana L.) (Hills 1959, Rowe 1972).

\section{Analysis}

A matrix of forest management and conservation planning objectives specific and relevant to the watershed was first developed to guide the interpretation of inventory and information needs. The objectives considered were: maintain and improve forest composition and structure, maintain and improve biodiversity, regeneration management, invasive species management and control, tree seed source management, biomass and carbon content estimates, species at risk (SAR) habitat management and conservation, climate change monitoring, maintenance of hydrological integrity, and natural heritage systems planning and design. This list was compiled based on the objectives and needs that are most often considered in southern Ontario, but it is neither exhaustive nor were all elements considered and analyzed in this study. 


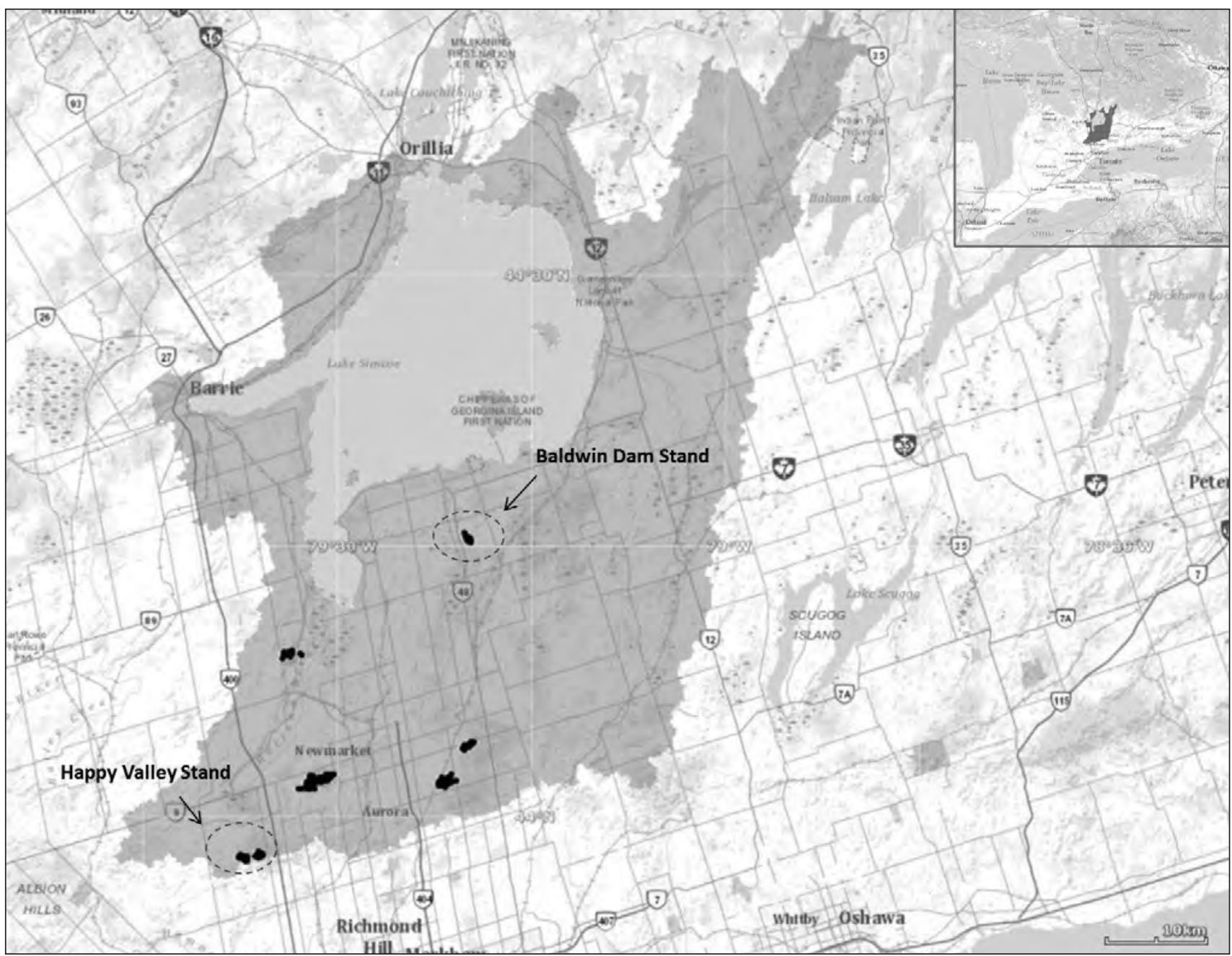

Fig. 1. Plot location within the Lake Simcoe watershed and LS location in Ontario (upper right corner). Happy Valley and Baldwin Dam stands are outlined on the map.

VSP sampling was conducted over a number of public and private forests within the watershed (Fig. 1). Plot locations followed a systematic grid that was GIS-generated based on a random start. Circular plots were spaced at either a $250 \mathrm{~m}$ or $500 \mathrm{~m}$ distance, depending on stand size, accessibility, resources, and time constraints. Diameter at breast height (DBH) of all trees was measured within each of the $400 \mathrm{~m}^{2}$ plots. Full vegetation species lists with absolute cover for vegetation at vertical strata $(>10 \mathrm{~m}, 2-10 \mathrm{~m}, 0.5-2 \mathrm{~m})$ were also measured for 105 plots.

The analysis was done at the stand level for the two selected stands following the forest management and conservation planning matrix and information needs. The stands analyzed were: a) the Nature Conservancy Canada (NCC) property at Happy Valley Forest (HV), classified to ELC Vegetation Type (Lee et al. 1998) as Dry-Fresh Sugar Maple Deciduous Forest Type (FOD5-1) with six VSP plots; and b) the Lake Simcoe Region Conservation Authority (LSRCA) property at Baldwin Dam (BD), classified to community series (Mixed Forest-FOM), with seven VSP plots.

VSP plot information within the two stands was used to derive tree density, basal area and species distributions at the stand level. Mean absolute and relative abundance by species by layer were also calculated and compared to the description of the vegetation type FOD5-1 for the HV stand. Forest regeneration was also measured as a count of stems per plot and extrapolated to the stand. Diversity for the two stands was quantified using species richness (total, native and nonnative), abundance and Shannon-Weiner Diversity Index. In addition, diversity was measured using the floristic quality assessment index, which assigns a co-efficient of conservatism (CC) to each species (Oldham et al. 1995). Based on this method, native species are ranked between 1 and 10 , where at the lower end are species that inhabit a wide range of plant communities and under a variety of disturbance conditions, while values of 9 and 10 are reserved for species that occupy a narrow range of synecological parameters and are intolerant of disturbance. Non-native species are given a coefficient of weediness (WEED) that range from -1, having little impact on the native vegetation, to -3 , invasives having the potential to significantly impact native plant communities. Natural Area Index (NAI) for all sites and the two stands was then calculated by multiplying the mean CC score for all species by the square root of the number of native species 

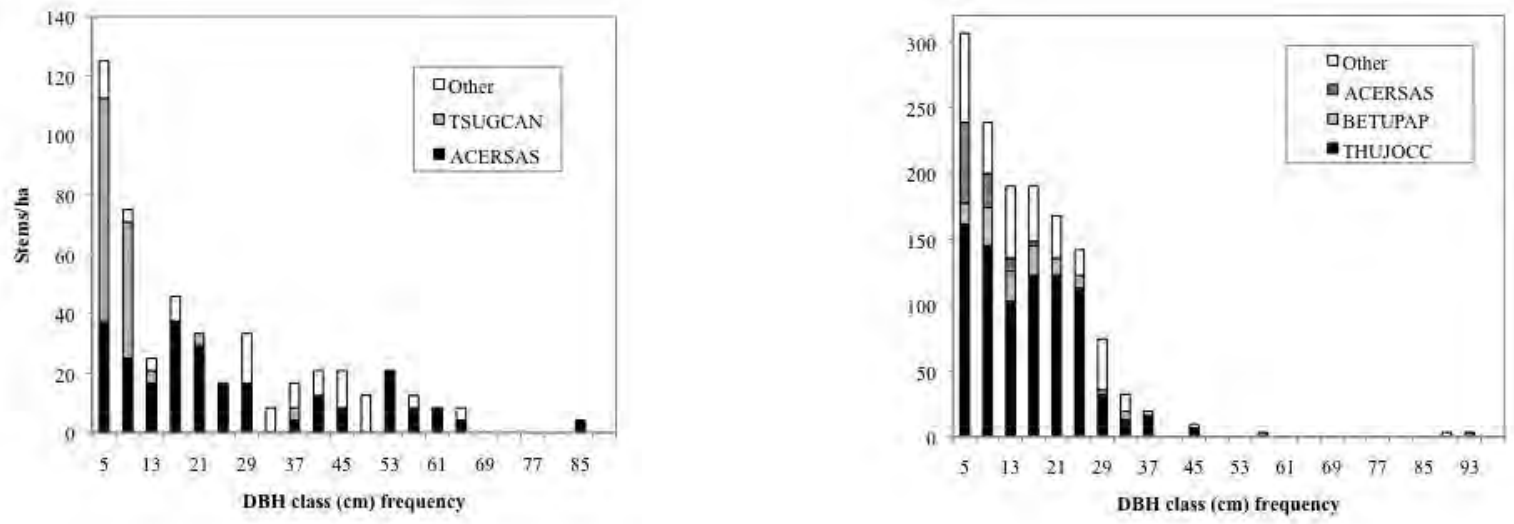

Fig. 2. Tree density of the two stands. Happy Valley (left) stems per ha including dominant species sugar maple (ACERSAS) and eastern hemlock (TSUGCAN). Baldwin Dam (right) stems per ha by size class including dominant species eastern white cedar (THUJOCC), white birch (BETUPAP) and sugar maple (ACERSAS). "Other" refers to the combined mean stem density of all other species measured.
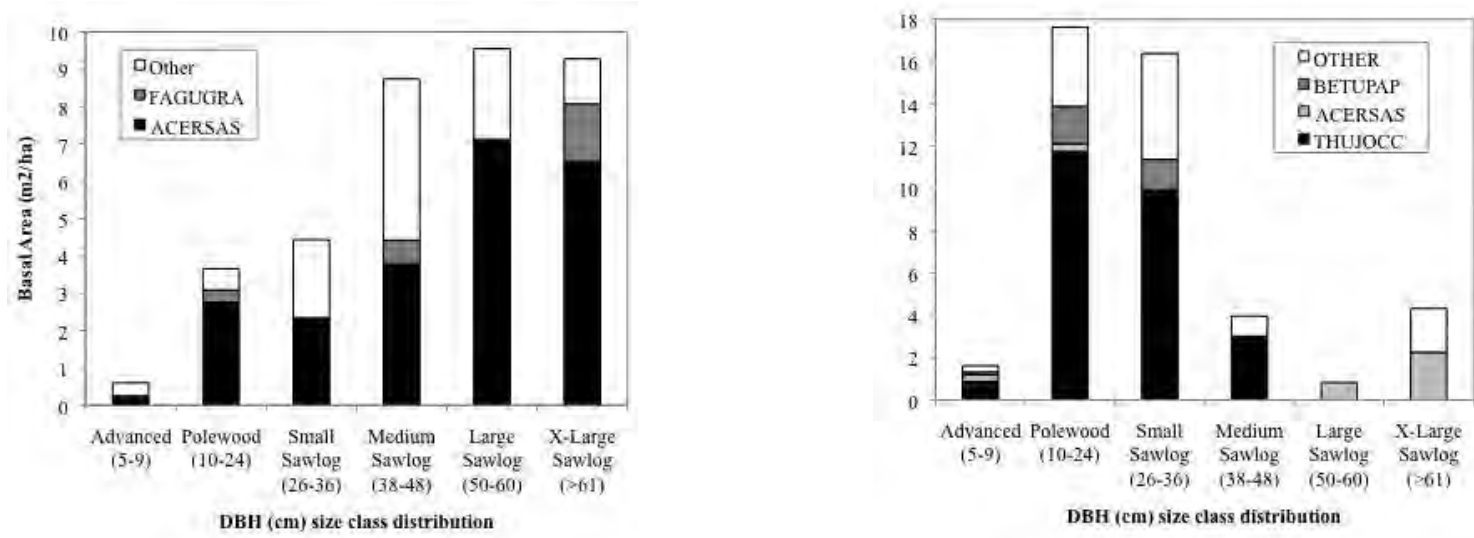

Fig. 3. Basal area by size class distribution of the two stands. Happy Valley (left) basal area by size class and dominant species sugar maple (ACERSAS) and American beech (FAGUGRA). Baldwin Dam (right) basal area by size class and dominant species eastern white cedar (THUJOCC), sugar maple (ACERSAS), white birch (BETUPAP). "Other" refers to the combined mean basal area of all other species measured.

(Oldham et al. 1995). Those sites with the highest NAI scores have a combination of high native species richness and species with high CC scores (Burke et al. 2008). Finally, above-ground live wood biomass estimates were calculated for standing live trees using a set of allometric equations (Lambert et al. 2005). Biomass was converted to carbon content using species-specific carbon percentages (Lamlom and Savidge 2003) and the average of 0.47 was used when speciesspecific percentages were unavailable (McGroddy et al. 2004, IPCC 2006).

\section{Results and Discussion}

\section{Forest composition and structure}

Stem density was derived as a measure of the species frequency distribution by diameter classes (Fig. 2). The HP stand had a mean density of 487 stems per ha. The smaller diameter classes and saplings are dominated by eastern hem- lock and sugar maple, while the larger classes tend to be dominated by sugar maple. The BD stand had a higher mean density of 1384 stems per ha, where saplings and polewood were dominated by eastern hemlock. Medium to large size class ranges are less frequent, indicating a young stand with an emergent eastern white cedar, sugar maple and white birch (Betula papyrifera Marsh.) population.

Stand structure and distribution was further assessed using basal area by size class as this provides necessary information to support stand management for timber (Fig. 3). The $\mathrm{HV}$ stand is well stocked and is structurally dominated at all size classes by sugar maple with a mean basal area of $36.3 \mathrm{~m}^{2} \mathrm{ha}^{-1}$. For this stand, the larger trees could be targeted to reduce the basal area and allow release of the smaller size classes. This would also allow for openings in the canopy to ensure forest regeneration and recruitment of a viable young cohort. Similar analysis for the BD stand indicates a stand in 
transition from early to late succession. This stand has a mean basal area of $45.1 \mathrm{~m}^{2} \mathrm{ha}^{-1}$, with the representation greatest amongst the polewood and small sawlog classes. In this stand, management options could include thinning to reduce basal area and to release the younger cohort in order to ensure a healthy future population with adequate stocking (OMNR 1998).

Restoration of forest stand conditions to resemble mature or old-growth stand composition, structure and functions are often goals of forest conservation. While there is no inventory and information to provide a basis of reference and comparison for stand or forest condition in the LS watershed, some assessments of quality and change can be done using examples of mature forest from similar regions. For example, mature and old-growth stands of the deciduous forests of the Great Lakes - St. Lawrence forest typically have a mean basal area of $>29 \mathrm{~m}^{2} \mathrm{ha}^{-1}$ (Keddy and Drummond 1996, McGee et al. 1999). Mean stem density per hectare in a northern hardwood forest in the Adirondacks ranged from $508(+/-107)$ in mature stands and $392(+/-46)$ in old-growth stands (McGee et al. 1999). Mature and old-growth stands are generally dominated by only a few tolerant species such as sugar maple and American beech, whereas younger stands have a higher compositional diversity, comprised of mid- and intolerant species, indicative of more recent disturbance (Keddy and Drummond 1996). While BD stand has a high density of small size class trees, HV stand has a density, basal area, and tree composition analogous to reference measurements of mature/oldgrowth from other study sites in similar forest types.

HV stand canopy is dominated by sugar maple, with associates white ash, American beech, basswood, red oak, eastern hemlock, bitternut hickory (Carya cordiformis [Wangenh.] K. Koch), and black cherry (Prunus serotina Ehrh.). This tree composition was similar to the ELC class description, but the mean relative abundances of the dominant species for the HV stand demonstrates a more diverse and variable composition and structure than what the ELC class implies. The most dominant herb in the stand was broadleaf enchanter's nightshade (Circaea lutetiana L. ssp. canadensis [L.] Asch. \& Magnus) (24\% mean cover).

Structural attributes of a forest are important as they can act as a surrogate for functions and habitat of organisms that are difficult to measure directly (OMNR 1998, Franklin et al. 2002, Lindenmayer et al. 2006). Forest structure and composition can aid in identifying critical habitat, a primary objective for SAR protection and management in Ontario. For example, the Acadian flycatcher (Empidonax virescens Vieillot) is often associated with mature sugar maple-beech forest, but is also highly specific and requires a variety of forest structure throughout its life-cycle (COSEWIC 2010). VSP data for $\mathrm{HV}$ stand shows, besides forest type, that the understory cover is relatively sparse and that there is a high basal area in the stand to support this species.

\section{Forest regeneration management}

The VSP, in addition to abundance measurements of regeneration, incorporates sub-plots that allow quantifying and monitoring tree regeneration more systematically and using it as an indication of future stand composition and its long-term persistence. HV had a total mean regeneration density of 633 stems per ha, with a high representation of seedling recruitment for both sugar maple and American beech. This indi- cates that the stand has a more than adequate amount of recruitment to replace trees that die or fall due to small-scale disturbances of gap-phase dynamics. Regeneration sub-plots showed a dominance of sugar maple and white ash regeneration. Without management intervention, it may be predicted that sugar maple will continue under the mean $78 \%$ canopy closure, as it is a shade-tolerant species with the ability to survive in low light as a sapling and release when a gap is created (OMNR 1998). White ash can persist in low light levels at a very young age, but requires increasingly more light as it matures, at approximately $45 \%$ canopy closure for optimal growth (OMNR 1998). In the BD stand, regeneration is at a lower density (42 stems per ha), and it is primarily white cedar. White cedar, for parts of the stand, forms a canopy with little light influx, and as a result, seedling recruitment underneath is quite low because of this species' slow growing and light demanding nature (Burns and Honkala 1990). Common buckthorn (Rhamnus cathartica L.) was found in this stand in relatively high abundances in both the $2-10 \mathrm{~m}$ and $0.5-2 \mathrm{~m}$ vertical strata with mean relative covers of $33 \%$ and $52 \%$, respectively. Dog-strangling vine (Cynanchum rossicum [Kleopow] Borhidi) and common buckthorn were also relatively abundant in the ground layer, at $7 \%$ and $5 \%$, respectively. The reason for this could be that $\mathrm{BD}$ is a small area with a high degree of edge effects and a proportionally high trail network. It is suspected that for this area native tree regeneration will be impacted by common buckthorn, which is highly competitive (Knight et al. 2007). Both species also have the ability to form dense monocultures under varying levels of light availability in the understory (Knight et al. 2007, Smith et al. 2007). Other important invasive species that were found in $\mathrm{HV}$ are garlic mustard (Alliaria petiolata [M. Bieb.] Cavara \& Grande) and Tatarian honeysuckle (Lonicera tatarica L.). While neither was found in large abundance within the two stands, both pose threats to native forest vegetation in the LS watershed.

\section{Maintenance and improvement of biodiversity Species richness and diversity}

Total richness for the HV stand was 62 species. Of these, 55 species $(88.7 \%)$ are native and $7(11.3 \%)$ are non-native. Total richness for the $\mathrm{BD}$ stand was 70 . Of these, $61(87.1 \%)$ were native and $9(12.9 \%)$ were non-native. Shannon-Weiner diversity index for ground vegetation $(<0.5 \mathrm{~m})$ showed a higher diversity in the BD stand (3.04) than in the HV stand (2.67). These also reflected a greater evenness in the BD stand. The mature HV stand however, scored higher (1.20) on the index for herb cover than $\mathrm{BD}$ (1.08). While high richness may indicate a high-quality site, it does not necessarily consider the local ecology, composition, and levels of disturbance. Furthermore, complete evenness (value of 1) does not necessarily reflect a natural system where species exist in varying, inequitable abundances. The younger BD stand, for example, had a higher richness and greater evenness and ranked higher on the Shannon-Weiner diversity index. This may, however, be more indicative of increased disturbance than floristic diversity. Disturbance can promote higher diversity by immigration of generalist species at the expense of less common or specialist species (Burke et al. 2008). HV stand's higher herb diversity is also an important indicator of mature forests. Herbs such as Canada mayflower (Maianthemum canadense Desf.), white trillium (Trillium grandiflorum 
Table 1. Richness, NAl, mean CC and WEED for the two sample stands.

\begin{tabular}{lcccccc}
\hline & Richness Native & Non-native & Total & NAI & CC average & Weed average \\
\hline Happy Valley & 55 & 7 & 62 & 28.70 & 3.87 & -2.29 \\
Baldwin Dam & 61 & 9 & 70 & 25.66 & 3.29 & -2.22 \\
\hline
\end{tabular}

[Michx.] Salisb.) and bloodroot (Sanguinaria canadensis L.) are generally associated with undisturbed sites as well as mature and old-growth deciduous temperate forests (Keddy and Drummond 1996, Rayfield et al. 2005).

\section{Vegetation quality based on the Floristic Quality Assess- ment system}

Mean coefficients of conservatism (CC) can be used to assess a stand or site's overall floristic quality. A site with a number of high-ranking species (i.e., 7-10) indicates a site that experiences little or no disturbance and that can therefore support specialist species. Natural Area Index (NAI) is another measure of site quality. While BD stand ranked higher for diversity, HV stand had a higher NAI and CC, indicating that HV has higher floristic quality (Burke et al. 2008) (Table 1), while WEED for both stands was in a similar range (Table 1).

Snags, cavity (standing dead or dying trees) and mast trees are indicators of a stand's potential to support mammalian and avian diversity. Information on these is necessary to guide how a stand may be managed or restored in order to provide habitat for such diversity. HV stand, with a mean mast tree density of 39.5 mast trees per ha ( $\geq 25 \mathrm{~cm} \mathrm{DBH}), 53 \%$ of which is comprised of beech and oak, has a mean snag density typical of old growth (Keddy and Drummond 1996). Conversely, BD stand's snag density (29 mast trees per ha) and lower mast diversity (67\% of which were ironwood (Ostrya virginiana [Mill.] K. Koch var. virginiana) is more indicative of a younger stand with less wildlife potential. Current snag densities and size information can also be used to indicate future down woody debris stocking, which is critical for small mammal, insect and salamander populations.

\section{Biomass and carbon content estimates}

Estimation of biomass density and carbon content is essential in accounting for carbon budgets (Lambert et al. 2005). Currently, voluntary carbon markets exist, which may be an option for generating income from forest conservation and improved forest management (Lamlom and Savidge 2003). While programs such as NFI can give a broad estimation of forest biomass across the country, its scale is too coarse for local and site-specific use (Hall et al. 2010), as there is just one NFI plot in the watershed. Thus, an inventory approach that is applicable to the local scale and can be easily implemented by different groups in the watershed is necessary. To demonstrate this, the VSP tree data were used to estimate live aboveground biomass based on DBH allometric formulas (Lambert et al. 2005) in order to estimate live carbon (Lamlom and Savidge 2003). HV, dominated by large hardwood species, had a total carbon content of $21.89 \mathrm{Mg} \mathrm{C}$ per six plots equalling $0.24 \mathrm{ha}$. This number was extrapolated to the stand to yield $91.22 \mathrm{Mg} \mathrm{C} / \mathrm{ha}$. $\mathrm{BD}$, dominated by medium-sized white cedar had a total carbon content of $19.43 \mathrm{Mg} C$ per 10 plots equalling $0.31 \mathrm{ha}$, or $62.67 \mathrm{Mg} \mathrm{C} / \mathrm{ha}$.

\section{Conclusions}

Forests are spatially and temporally dynamic and require continued monitoring to understand the changes that are occurring under a variety of stresses in southern Ontario. Forest inventory and monitoring to support the LSPP program and the myriad goals of forest management and conservation planning in the LS watershed must be integrative, strategic, standardized and yet flexible to enable reporting on the biodiversity, ecological health, and habitat quality of the natural heritage of the LS watershed (OME 2009).

Inventory and monitoring in the watershed must extend beyond vegetation classes/types that are easy to delineate and generalize, but alone do not provide adequate information that can quantify and measure internal and external variability, and detect and assess changes over time. More specific site-level, quantitative base information on structure, composition, along with environmental characteristics (i.e., topography, soil, vernal pools) is necessary to fully assess the existing condition, measure changes and support adaptive management. This can be achieved by collecting plot-level inventory information that can be repeated over space and time, analyzed at different scales from plot and stand to landscapes, and that can be coupled with other spatial information. This study has demonstrated that plot-based information can be used to derive structural and compositional diversity, estimate species richness, quantify different diversity measures, measure abundance, basal area, biomass and carbon, and quantity invasive species and SAR habitats. These quantifications and measures derived from VSP data are monitoring measures, but also serve as base information to help managers prioritize sites for forest management and conservation and define specific action.

\section{Acknowledgments}

We would like to thank Kate Gee and Elizabeth Stanley of the Ontario Ministry of Natural Resources, Aurora District, Lake Simcoe Region Conservation Authority, York Region (Forestry), and the Nature Conservancy of Canada.

\section{References}

Brinker, S. and C. Jones. 2010. Identifying provincially rare species (Species at Risk) vulnerable to climate change in the Lake Simcoe watershed, Ontario, Canada. Available from http://www.climateontario.ca/doc/workshop/2011LakeSimcoe/Vulnerability\%20Assessments/Species\%20at\%20Risk-Brinker\%20Jones.pdf

Burke, D.M., K.A. Elliott, S.B. Holmes and D. Bradley. 2008. The effects of partial harvest on the understory vegetation of southern Ontario woodlands. Forest Ecol. and Manag. 255: 2204-2212.

Burns, R.M. and B.H. Honkala (tech. coords.). 1990. Silvics of North America: 1. Conifers; 2. Hardwoods. Agriculture Handbook 654, U.S. Dept. of Agriculture, Forest Service, Washington, DC. vol.2. $877 \mathrm{p}$.

[COSEWIC] Committee on the Status of Endangered Wildlife in Canada. 2010. COSEWIC assessment and status report on the Aca- 
dian Flycatcher Empidonax virescens in Canada.. Ottawa. $\mathrm{x}+38$ p. Available from http://publications.gc.ca/collections/collection_ 2011/ec/CW69-14-5-2010-eng.pdf.

Drysdale, C., L-A. Hayek, M. Doyle, S. O'Grady and D. Kehler. 2007. Experimental design considerations for plot-based monitoring; a discussion paper. Prepared by Sustainable Ecosystem Management Systems (Nova Scotia) Ltd. for Environment Canada, Ecological Monitoring and Assessment Network Coordinating Office.

Franklin, J.F. et al. 2002. Disturbances and structural development of natural forest ecosystems with silvicultural implications, using Douglas-fir forests as an example. Forest Ecol. and Manag. 155: 399-423.

Gillis, M.D. 1988. Estimating change from successive static forest inventories. For. Chron. 64(4): 352-354.

Gillis, M.D. 2001. Canada's National Forest Inventory (responding to current information needs). Environ. Monit. and Assess. 67: 121-129.

Gillis, M. D., P. Boudewyn, K. Power and G. Russo. 2010. Canada. In E. Tomppo, D. Gschwantner, M. Lawrence and R.E. McRoberts (eds.). National forest inventories - Pathways for common reporting. pp. 97-111. Springer, New York.

Gillis, M.D., A.Y. Omule and T. Brierley. 2005. Monitoring Canada's forests: The National Forest Inventory. For. Chron. 81(2): 214-221.

Hall, R.J., R.S. Skakun, A. Beaudoin, M.A. Wulder, E.J. Arsenault, P.Y. Bernier, L. Guindon, J.E. Luther and M.D. Gillis. 2010. Approaches for forest biomass estimation and mapping in Canada. IGARSS :1988-1991.

Hills, G.A. 1959. A ready reference to the description of the land of Ontario and its productivity. Preliminary report. Division of Research, Ontario Department of Lands and Forests, Maple, ON. $142 \mathrm{p}$.

[IPCC] Intergovernmental Panel on Climate Change. 2006. IPCC Guidelines for National Greenhouse Gas Inventories. Prepared by the National Greenhouse Gas Inventories Programme. H.S. Eggleston, L. Buendia, K. Miwa, T. Ngara and K. Tanabe (eds.).

Keddy, P.A. and C.G. Drummond. 1996. Ecological properties for the evaluation, management, and restoration of temperate deciduous forest ecosystems. Ecol. Appl. 6(3): 748-762.

Knight, K.S., J.S. Kurylo, A.G. Endress, J.R. Stewart and P.B. Reich. 2007. Ecology and ecosystem impacts of common buckthorn (Rhamnus cathartica): a review. Biol. Invasions 9: 925-937.

[LSSAC] Lake Simcoe Science Advisory Committee. 2008. Lake Simcoe and its watershed: report to the Minister of the Environment. Queen's Printer for Ontario.

Lambert, M.C., C.H. Ung and F. Raulier. 2005. Canadian national tree aboveground biomass equations. Can. J. For. Res. 35: 1996-2018.

Lamlom, S.H. and R.A. Savidge. 2003. A reassessment of carbon content in wood: variation within and between 41 North American species. Biomass and Bioenergy 25: 381-388.

Lee, H.T., W.D. Bakowsky, J. Riley, J. Bowles, M. Puddister, P. Uhlig and S. McMurray. 1998. Ecological Land Classification for Southern Ontario: First Approximation and Its Application. South Central Science Section, Science Development and Transfer Branch, Ontario Ministry of Natural Resources. SCSS Field Guide FG-02.

Lindenmayer, D.B., J.F. Franklin and J. Fischer. 2006. General management principles and a checklist of strategies to guide forest biodiversity conservation. Biol. Conserv. 131: 433-445.
McGee, G.G., D.J. Leopold and R.D. Nyland. 1999. Structural characteristics of old-growth, maturing, and partially cut northern hardwood forests. Ecol. Appl. 9(4): 1316-1329.

McGroddy, M.E., T. Daufresene and L.O. Hedin. 2004. Scaling of $\mathrm{C}: \mathrm{N}: \mathrm{P}$ stoichiometry in forests worldwide: Implications of terrestrial redfield-type ratios. Ecology 85(9): 2390-2401.

Noss, R.F. 2004. Information needs for large-scale conservation planning. Nat. Areas J. 24: 223-231.

Oldham, M.J., W.D. Bakowsky and D.A. Sutherland. 1995. Floristic Quality Assessment System for Southern Ontario. Natural Heritage Information Centre, Ontario Ministry of Natural Resources, Peterborough, $\mathrm{ON}$.

[OMNR] Ontario Ministry of Natural Resources. 1998. A silvicultural guide to tolerant hardwoods in Ontario. Ont. Min. Nat. Resour. Queen's Printer for Ontario. Toronto, ON. 500 p.

2006. Forest Resources of Ontario: State of the Forest Report 2006. Forest Information Series. Available from http://www.mnr. gov.on.ca/en/Business/Forests/2ColumnSubPage/STEL02_179267. html.

2010. Lake Simcoe Protection Plan (LSPP): Monitoring Natural Heritage and Hydrologic Features of the Lake Simcoe Watershed.

[OME] Ontario Ministry of the Environment. 2009. Lake Simcoe Protection Plan. Queens Printer for Ontario, Toronto, ON. 28 p.

Puric-Mladenovic, D., J. Malcolm, H. She, S. Strobl and J.Buck. 2010. An analysis of the vulnerabilities of terrestrial ecosystems/vegetation cover to climate change in the Lake Simcoe watershed. Available from http://www.climateontario.ca/doc/workshop/2011Lake Simcoe/Vulnerability\%20Assessments/Vegetative\%20Cover-PuricMladenovic\%20Malcolm\%20She\%20Strobl\%20Buck.pdf.

Puric-Mladenovic, D., D. Bradley, S. Strobl and A. MacIntosh. 2009. Vegetation Sampling Protocol (VSP). Information Management and Spatial Analysis, Southern Science and information Section, Ontario Ministry of Natural Resources. Available from http://www.forestry.utoronto.ca/imsa/VSP/documents/VSP_Manual_v2.5_May25_2011.pdf.

Rayfield, B., M. Anand and S. Laurence. 2005. Assessing simple versus complex restoration strategies for industrially disturbed forests. Restor. Ecol. 13(4): 639-650.

Roberts-Pichette, P. and L. Gillespie 1999. Terrestrial vegetation biodiversity monitoring protocols. EMAN Occasional Paper Series, Report No. 9. Ecological Monitoring Coordinating Office, Burlington, $\mathrm{ON}$.

Rowe, J.S. 1972. Forest regions of Canada. Canadian Forestry Service Publication No. 1300, Department of Environment, Ottawa, ON. $172 \mathrm{p}$.

Smith, L.L., A. DiTommaso, J. Lehmann and S. Greipsson. 2007. Growth and reproductive potential of the invasive exotic vine Vincetoxicum rossicum in northern New York State. Can. J. Bot. 84: 1771-1780.

Yemshanov, D. D.W. McKenney and J.H. Pedlar. 2011. Mapping forest composition from the Canadian National Forest Inventory and land cover classification. Environ. Monit. Assess. doi: 10.1007/s10661-011-2293-2. 